\title{
Penerapan Aljabar Max-Plus Pada Permasalahan Penjadwalan Angkutan Perdesaan di Jombang
}

\author{
Nahlia Rakhmawati ${ }^{1}$, Ririn Febriyanti ${ }^{2}$ \\ STKIP PGRI Jombang ${ }^{1}$, rakhmanahlia.stkipjb@gmail.com ${ }^{1}$ \\ STKIP PGRI Jombang ${ }^{2}$, ririn_febriyanti00@ yahoo.com ${ }^{2}$
}

DOI:https://doi.org/10.15642/mantik.2017.3.2.51-56

\begin{abstract}
Abstrak
Keberadaan transportasi umum yang ideal masih menjadi cita-cita banyak kota di Indonesia, termasuk kota Jombang. Tingginya konsumsi masyarakat Jombang terhadap kendaraan bermotor, membuat macet jalanan pada daerah sekolah karena kebutuhan menjemput anak ketika jam pulang sekolah. Pada penelitian ini disusun sebuah graf berarah dari 3 trayek angkutan perdesaan untuk mendapatkan desain model penjadwalan menggunakan aljabar max-plus. Dari hasil analisis terhadap model diperoleh periode keberangkatan angkutan perdesaan $(l)$ adalah 10 menit sekali, dengan dua interval waktu keberangkatan awal. Jadwal keberangkatan yang disusun memungkinkan angkutan perdesaan selalu ada di setiap titik pertemuan selama jam pulang sekolah.
\end{abstract}

Kata kunci: jadwal keberangkatan, angkutan perdesaan, aljabar max-plus

\begin{abstract}
The existence of ideal public transportation is still a dream of many cities in Indonesia, including the city of Jombang. The high consumption of Jombang people to motor vehicles, causing traffic jams in the school area. In this research, a directed graph from 3 rural transit routes to get the design of scheduling model using max-plus algebra. From the analysis results to the model obtained the period of departure of rural transport is 10 minutes once, with two initial departure time interval. Arranged departure schedules allow rural transport always at every meeting point during school hours.
\end{abstract}

Keywords: departure schedule, rural transportation, max-plus algebra

\section{Pendahuluan}

Transportasi merupakan permasalahan yang selalu dihadapi oleh banyak kota di Indonesia terutama kota-kota yang telah maju ataupun kota yang sedang berkembang, baik di bidang transportasi perkotaan maupun transportasi regional antar kota [1]. Fenomena yang terjadi di banyak kota besar adalah tuntutan ekonomi yang perpedoman pada pendidikan masyarakat. Tingginya nilai yang diperoleh seseorang di sebuah sekolah menjadi modal utama seseorang dalam mencari pekerjaan. Tuntutan inilah yang membuat masyarakat berlomba-lomba untuk menyekolahkan putra putri mereka di sekolah yang terbaik di lingkungannya. Tak sedikit masyarakat yang mengupayakan sekolah bahkan diluar lingkungannya atau dengan kata lain lebih jauh dari tempat tinggalnya selama mereka masih mampu mengantar putra putri mereka sampai di sekolah.

Memusatnya sekolah tervaforit di kota Jombang membuat peningkatan volume kendaraan sering terjadi pada daerah persekitaran sekolah utamanya pada jam pulang sekolah. Menumpuknya kendaraan wali murid di sekitaran sekolah untuk menjemput putraputri mereka menyebabkan banyak jalan di Jombang padat. Ini merupakan fenomena yang 
biasa namun berbahaya, karena penumpukan kendaraan di sekitar sekolah membuat masyarakat menjadi lengah tentang peraturan berlalu lintas. Banyaknya kendaraan bermotor dan ketidakhati-hatian menambah jumlah kecelakaan yang sering terjadi di Jombang dan melibatkan siswa SMA/SMP yang belum memiliki SIM.

Terciptanya sistem transportasi yang dapat menjamin pergerakan manusia dan/atau barang secara lancar, aman, cepat, murah, dan nyaman merupakan tujuan utama pembangunan dalam sektor transportasi [2]. Bagitu juga tujuan pembangunan sektor transportasi di kabupaten Jombang. usaha yang telah dilakukan diantaranya adalah mentertibkan armada angkutan pedesaan yang keluar masuk terminal Kepuhsari dan pembangunan infrastruktur seperti halte di beberapa titik ramai. Pada penelitian sebelumnya, Nahlia telah mengkaji rancangan trayek baru di kota Jombang untuk mengatasi permasalahan peningkatan volume kendaraan di jam pulang sekolah [3]. Berdasarkan hasil yang diperoleh, yaitu sebuah desain penjadwalan, diperoleh sebuah skenario waktu keberangkatan yang cukup cepat dengan asumsi kendaraan yang digunakan adalah bus sekolah (bus khusus untuk pelajar). Rute yang diberikan pun menjangkau seluruh titik ramai di kota Jombang. namun, rancangan tersebut masih dinilai sulit direalisasikan mengingat pengadaan bus sekolah bukanlah sesuatu yang mudah.

Pada penelitian ini, digunakan 3 trayek angkutan pedesaan yang dinilai dalam kondisi yang optimal untuk dioperasikan di wilayah Jombang [4] sehingga harapannya solusi penjadwalan dapat lebih mengoptimalkan kinerja angkutan pedesaan di ketiga trayek tersebut.

\section{Transportasi Umum di Kota Jombang}

Sebagai daerah yang strategis, yaitu berada pada jalur utama yang menghubungan antar kota di Jawa Timur, Jombang sebenarnya telah memiliki infrastruktur pendukung transportasi yang laik. Namun, keberadaan angkutan pedesaan sebagai satu-satunya transportasi umum yang menghubungkan antar daerah di Jombang bahkan antar kabupaten di sekitar Jombang dirasa semakin menyusut dari tahun ke tahun.
Dari 25 trayek angkutan pedesaan yang beroperasi di Jombang [5], 6 diantaranya sudah tidak beroperasi sejak tahun 2000, sedangkan trayek lainnya masih beroperasi meskipun jumlah armadanya semakin sedikit.

Menyusutnya jumlah armada ini dikarenakan rendahnya minat masyarakat akan angkutan pedesaan yang beroperasi di Jombang. Tentu saja ada banyak alasan mengapa minat masyarakat menjadi sangat rendah terhadap angkutan pedesaan ini. WorldBank dan DirjenHubdat mengeluarkan standart yang harus dipenuhi untuk kinerja angkutan umum diantaranya adalah waktu perjalanan pergi pulang, frekuensi kendaraan, faktor muat, selisih waktu (Headway), jumlah trip dan jarak tempuh per kendaraan per hari, waktu siklus (Cycle Time), Jumlah penumpang per kendaraan per hari, Jumlah kendaraan dan waktu sirkulasi [4].

Pada penelitian ini akan disusun rancangan model penjadwalan angkutan pedesaan di Jombang yang meliputi 3 trayek yang dilalui oleh angkutan pedesaan dengan kode B, C dan G. Ketiga trayek ini digunakan karena berdasarkan penelitian oleh Mubarok, ketiga angkutan pedesaan inilah yang memenuhi kriteria cukup pada penilaian kinerjanya.

Selanjutnya untuk mempermudah menyusun rancangan model desain penjadwalan, dari ketiga trayek disusun sebuah graph berarah sederhana sebagaimana ditunjukkan oleh gambar 1 berikut ini.

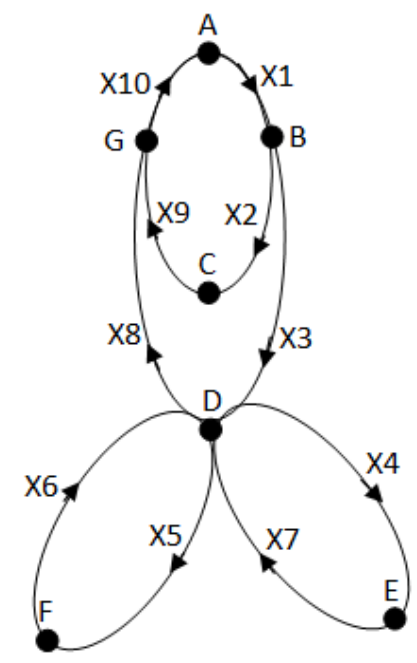

Gambar 1. Graph Berarah dari Ketiga Trayek Tabel 1. Waktu Tempuh dan Alokasi Jumlah Armada 


\section{JURNAL MATEMATIKA "MANTIK" \\ Edisi: Oktober 2017. Vol. 03 No. 02}

ISSN: 2527-3159

E-ISSN: 2527-3167

Dari gambar 1, diperoleh 3 titik pertemuan yaitu titik B (Jalan Gus Dur), titik D (Ploso) dan titik G (Halte Sambong). Ketiga titik ini memungkinkan penumpang untuk berpindah dari satu trayek ke trayek lainnya. Pada penelitian ini bobot graph ditentukan berdasarkan waktu tempuh antara masingmasing titik. Data lebih lengkap disajikan pada tabel 1 berikut ini.

\begin{tabular}{|c|c|c|c|c|c|}
\hline Var & $\begin{array}{c}\text { Ro } \\
\text { ut } \\
\text { e }\end{array}$ & From & To & $\begin{array}{l}\text { Trav } \\
\text { eling } \\
\text { Time } \\
\text { (min } \\
\text { utes) }\end{array}$ & $\begin{array}{l}\text { The } \\
\text { Num } \\
\text { ber } \\
\text { of } \\
\text { Arma } \\
\text { da }\end{array}$ \\
\hline $\mathrm{X} 1$ & 1 & $\begin{array}{l}\text { Terminal } \\
\text { (A) }\end{array}$ & $\begin{array}{l}\text { Jl. Gus } \\
\text { Dur (B) }\end{array}$ & 15 & 2 \\
\hline $\mathrm{X} 2$ & 1 & $\begin{array}{l}\text { Jl. Gus } \\
\text { Dur (B) }\end{array}$ & $\begin{array}{c}\text { Pasar } \\
\text { Gudo (C) }\end{array}$ & 30 & 3 \\
\hline $\mathrm{X} 9$ & 1 & $\begin{array}{c}\text { Pasar } \\
\text { Gudo (C) }\end{array}$ & $\begin{array}{c}\text { Halte } \\
\text { Sambong } \\
(\mathrm{G})\end{array}$ & 30 & 3 \\
\hline $\mathrm{X} 10$ & 1 & $\begin{array}{c}\text { Halte } \\
\text { Sambong } \\
(\mathrm{G})\end{array}$ & $\begin{array}{l}\text { Terminal } \\
\text { (A) }\end{array}$ & 20 & 2 \\
\hline $\mathrm{X} 1$ & 2 & $\begin{array}{l}\text { Terminal } \\
\text { (A) }\end{array}$ & $\begin{array}{c}\text { Jl. Gus } \\
\text { Dur (B) }\end{array}$ & 15 & 2 \\
\hline $\mathrm{X} 3$ & 2 & $\begin{array}{c}\text { Jl. Gus } \\
\text { Dur (B) }\end{array}$ & Ploso (D) & 30 & 3 \\
\hline $\mathrm{X} 4$ & 2 & Ploso (D) & $\begin{array}{l}\text { Ngusikan } \\
\text { (E) }\end{array}$ & 20 & 2 \\
\hline $\mathrm{X} 7$ & 2 & $\begin{array}{l}\text { Ngusikan } \\
\text { (E) }\end{array}$ & Ploso (D) & 15 & 2 \\
\hline $\mathrm{X} 8$ & 2 & Ploso (D) & $\begin{array}{c}\text { Halte } \\
\text { Sambong } \\
(\mathrm{G})\end{array}$ & 20 & 2 \\
\hline $\mathrm{X} 10$ & 2 & $\begin{array}{c}\text { Halte } \\
\text { Sambong } \\
(\mathrm{G})\end{array}$ & $\begin{array}{l}\text { Terminal } \\
\text { (A) }\end{array}$ & 20 & 2 \\
\hline $\mathrm{X} 1$ & 3 & $\begin{array}{l}\text { Terminal } \\
\text { (A) }\end{array}$ & $\begin{array}{l}\text { Jl. Gus } \\
\text { Dur (B) }\end{array}$ & 15 & 2 \\
\hline $\mathrm{X} 3$ & 3 & $\begin{array}{l}\text { Jl. Gus } \\
\text { Dur (B) }\end{array}$ & Ploso (D) & 30 & 3 \\
\hline $\mathrm{X} 5$ & 3 & Ploso (D) & $\begin{array}{c}\text { Tapen } \\
\text { (F) }\end{array}$ & 20 & 2 \\
\hline $\mathrm{X} 6$ & 3 & Tapen $(\mathrm{F})$ & Ploso (D) & 20 & 2 \\
\hline $\mathrm{X} 8$ & 3 & Ploso (D) & $\begin{array}{c}\text { Halte } \\
\text { Sambong } \\
(\mathrm{G})\end{array}$ & 20 & 2 \\
\hline $\mathrm{X} 10$ & 3 & $\begin{array}{c}\text { Halte } \\
\text { Sambong } \\
\text { (G) }\end{array}$ & $\begin{array}{l}\text { Terminal } \\
\text { (A) }\end{array}$ & 20 & 2 \\
\hline
\end{tabular}

\section{Aljabar Max-Plus}

Definisi 1. Definisi aljabar max-plus[6]

Diberikan $R_{\varepsilon} \stackrel{\text { def }}{=} R \cup\{\varepsilon\}$ dengan $R$ adalah himpunan semua bilangan real dan $\varepsilon=-\infty$. Pada $R_{\varepsilon}$ didefinisikan operasi berikut :

$\forall x, y \in R_{\varepsilon}, x \oplus y \stackrel{\text { def }}{=} \max \{x, y\}$ dan $x \otimes y \stackrel{\text { def }}{=} x+y$.

Himpunan matriks di dalam aljabar maxplus dinyatakan dalam $R_{\max }^{n \times m}$. Untuk $n \in N$ didefinisikan $\underline{n}=\{1,2,3, \ldots, n\}$. Elemen dari matriks $A \in R_{\max }^{n \times m}$ pada baris ke- $i$ dan kolom ke- $j$ dinyatakan dengan $a_{i j}$ untuk $i \in \underline{n}$ dan $j \in \underline{m}$ Dalam hal ini matriks $A$ ditulis sebagai

$$
A=\left(\begin{array}{cccc}
a_{1,1} & a_{1,2} & \ldots & a_{1, m} \\
a_{2,1} & a_{2,2} & \ldots & a_{2, m} \\
\vdots & \vdots & \ddots & \vdots \\
a_{n, 1} & a_{n, 2} & \ldots & a_{n, m}
\end{array}\right) .
$$

Ada kalanya elemen $a_{i j}$ juga dinotasikan sebagai $[A]_{i, j}, \quad i \in \underline{n}, j \in \underline{m}$.

Penjumlahan matriks $A, B \in R_{\max }^{n \times m}$ dinotasikan oleh $A \oplus B$ didefinisikan oleh

$$
\begin{aligned}
{[A \oplus B]_{i, j} } & =a_{i, j} \oplus b_{i, j} \\
& =\max \left\{a_{i, j}, b_{i, j}\right\} \text { untuk } i \in \underline{n} \text { dan } j \in \underline{m}
\end{aligned}
$$

Untuk matriks $A \in R_{\max }^{n \times p}$ dan $B \in R_{\text {max }}^{p \times m}$ perkalian matriks $A \otimes B$ didefinisikan sebagai

$$
\begin{aligned}
{[A \otimes B]_{i, j} } & =\bigoplus_{k=1}^{p} a_{i, k} \otimes b_{k, j} \\
& =\max _{k \in \underline{p}}\left\{a_{i, k}+b_{k, j}\right\}, \text { untuk } i \in \underline{n} \text { dan } j \in \underline{m}
\end{aligned}
$$

Misalkan matriks $A \in R_{\max }^{n \times n}$, suatu graph berarah dari matriks $A$ adalah $G(A)=(E, V)$. Graph $G(A)$ mempunyai $n$ titik, himpunan semua titik dari $G(A)$ dinyatakan oleh $V$. Suatu garis dari titik $j$ ke titik $i$ ada bila $a_{i j} \neq \varepsilon$, garis ini dinotasikan 
oleh $(j, i)$. Himpunan semua garis dari graph $G(A)$ dinotasikan oleh $E$. Bobot dari garis $(j, i)$ adalah nilai dari $a_{i j}$ yang dinotasikan oleh $w(j, i)=a_{i, j} \in R_{\max }$. Bila $a_{i, j}=\varepsilon$, maka garis $(j, i)$ tidak ada [7].

Algoritma untuk menentukan nilai eigen dan vektor eigen dari matriks $A \in R_{\mathrm{max}}^{n \times n}$ dilakukan secara berulang dari bentuk persamaan linear

$$
x(k+1)=\bigoplus_{p=1}^{M}\left(A_{p} \otimes x(k+1-p)\right)
$$

dengan $M$ adalah jumlah maksimum armada di setiap trayek.

Teorema 2.[7] Bila untuk sebarang keadaan awal $\quad x(0) \neq \varepsilon \quad$ sistem persamaan (*) memenuhi $x(p)=c \otimes x(q)$ untuk beberapa bilangan bulat $p$ dan $q$ dengan $p>q \geq 0$ dan beberapa bilangan real $c$, maka

$$
\lim _{k \rightarrow \infty}=\frac{x(k)}{k}=\left[\begin{array}{llll}
\lambda & \lambda & \ldots & \lambda
\end{array}\right]^{T}
$$

dengan $\lambda=\frac{c}{p-q}$. Selanjutnya $\lambda$ adalah suatu nilai eigen dari matriks $A$ dengan vektor eigen diberikan oleh

$$
\boldsymbol{v}=\bigoplus_{i=1}^{p-q}\left(\lambda^{\otimes(p-q-i)} \otimes x(q+i-1)\right) .
$$

Berdasarkan teorema 2, menginspirasi suatu algoritma untuk mendapatkan nilai eigen sekaligus vektor eigen dari suatu matriks persegi A yang dikenal dengan Algoritma Power [5], yaitu sebagai berikut:

1. Mulai dari sebarang vektor awal $x(0) \neq \varepsilon$.

2. Iterasi persamaan $(*)$ sampai ada bilangan bulat $p>q \geq 0$ dan bilangan real $c$ sehingga suatu perilaku periodik terjadi, yaitu $x(p)=c \otimes x(q)$.

3. Hitung nilai eigen $\lambda=\frac{c}{p-q}$.

4. Hitung vektor eigen

$$
\boldsymbol{v}=\bigoplus_{i=1}^{p-q}\left(\lambda^{\otimes(p-q-i)} \otimes x(q+i-1)\right) .
$$

\section{Model Penjadwalan Transportasi Umum di Kota Jombang}

Sebelum disusun model maka terlebih dahulu akan dilakukan sinkronisasi keberangkatan armada angkutan pedesaan di masing-masing variabel. Tujuan sinkronisasi adalah untuk mendapatkan rancangan waktu tunggu yang dibutuhkan agar rancangan model yang akan disusun mewakili keadaan yang dimodelkan. Aturan sinkronisasi yang digunakan adalah sebagai berikut:

\section{Trayek 1.}

a. Keberangkatan armada ke-(k+1) dari A menuju ke $\mathrm{B}$ menunggu kedatangan armada ke-(k-1) dari G menuju ke A.

b. Keberangkatan armada ke-(k+1) dari $\mathrm{B}$ menuju ke $\mathrm{C}$ menunggu kedatangan armada ke-(k-1) dari A menuju B.

c. Keberangkatan armada ke-(k+1) dari $\mathrm{C}$ menuju $\mathrm{G}$ menunggu kedatangan armada ke-(k-2) dari B menuju ke C.

d.Keberangkatan armada ke-(k+1) dari $G$ menuju ke $\mathrm{A}$ menunggu kedatangan armada ke-(k) dari $\mathrm{C}$ menuju $\mathrm{G}$ dan kedatangan armada ke-(k-2) dari D menuju ke G.

\section{Trayek 2.}

a. Keberangkatan armada ke- $(\mathrm{k}+1)$ dari A menuju ke $\mathrm{B}$ menunggu kedatangan armada ke-(k-1) dari G menuju ke A.

b. Keberangkatan armada ke-(k+1) dari $\mathrm{B}$ menuju ke $\mathrm{D}$ menunggu kedatangan armada ke-(k-1) dari A menuju ke B.

c. Keberangkatan armada ke-(k+1) dari D menuju ke $\mathrm{E}$ menunggu kedatangan armada ke-(k-2) dari B menuju ke D dan kedatangan armada ke-(k-1) dari E menuju ke D serta kedatangan armada ke-(k-1) dari F menuju ke D.

d.Keberangkatan armada ke- $(k+1)$ dari $E$ menuju ke $\mathrm{D}$ menunggu kedatangan armada ke-(k-1) dari D menuju ke E.

e. Keberangkatan armada ke-(k+1) dari $\mathrm{D}$ menuju ke $G$ menunggu kedatangan armada ke-(k-2) dari B menuju ke D dan kedatangan armada ke-(k-1) dari E menuju 
ke D serta kedatangan armada ke-(k-1) dari F menuju ke D.

f. Keberangkatan armada ke-(k+1) dari $G$ menuju ke A menunggu kedatangan armada ke-(k-2) dari $\mathrm{C}$ menuju ke $\mathrm{G}$ dan kedatangan armada ke-(k-1) dari D menuju ke G.

\section{Trayek 3.}

a. Keberangkatan armada ke- $(\mathrm{k}+1)$ dari $\mathrm{A}$ menuju ke $\mathrm{B}$ menunggu kedatangan armada ke-(k-1) dari G menuju ke A.

b. Keberangkatan armada ke- $(\mathrm{k}+1)$ dari $\mathrm{B}$ menuju ke $\mathrm{D}$ menunggu kedatangan armada ke-(k-1) dari A menuju ke B.

c. Keberangkatan armada ke- $(k+1)$ dari $D$ menuju ke $\mathrm{F}$ menunggu kedatangan armada ke-(k-2) dari $\mathrm{B}$ menuju ke $\mathrm{D}$ dan kedatangan armada ke-(k-1) dari E menuju ke D serta kedatangan armada ke-(k-1) dari F menuju ke D.

d. Keberangkatan armada ke- $(\mathrm{k}+1)$ dari $\mathrm{F}$ menuju ke $\mathrm{D}$ menunggu kedatangan armada ke-(k-1) dari D menuju ke F.

e. Keberangkatan armada ke-(k+1) dari $\mathrm{D}$ menuju ke $\mathrm{G}$ menunggu kedatangan armada ke-(k-2) dari B menuju ke D dan kedatangan armada ke-(k-1) dari E menuju ke D serta kedatangan armada ke-(k-1) dari F menuju ke D.

f. Keberangkatan armada ke-(k+1) dari $G$ menuju ke A menunggu kedatangan armada ke-(k-1) dari C menuju ke $\mathrm{G}$ dan kedatangan D menuju ke G.

Berdasarkan aturan sinkronisasi seperti yang telah diuraikan, maka dapat dikonstruksi model keseluruhan trayek angkutan pedesaan sebagai berikut:

$$
\begin{aligned}
x_{1}(k+1) & =20 \otimes x_{10}(k-1) \\
x_{2}(k+1)= & 15 \otimes x_{1}(k-1) \\
x_{3}(k+1) & =15 \otimes x_{1}(k-1) \\
x_{4}(k+1)= & \left(30 \otimes x_{3}(k-2)\right) \oplus\left(20 \otimes x_{6}(k-1)\right) \\
& \oplus\left(15 \otimes x_{7}(k-1)\right) \\
x_{5}(k+1)= & \left(30 \otimes x_{3}(k-2)\right) \oplus\left(20 \otimes x_{6}(k-1)\right) \\
\oplus\left(15 \otimes x_{7}(k-1)\right) & \\
x_{6}(k+1)= & 20 \otimes x_{5}(k-1) \\
x_{7}(k+1)= & 15 \otimes x_{4}(k-1) \\
x_{8}(k+1)= & \left(30 \otimes x_{3}(k-2)\right) \oplus\left(20 \otimes x_{6}(k-1)\right) \\
\oplus\left(15 \otimes x_{7}(k-1)\right) & \\
x_{9}(k+1)= & 30 \otimes x_{2}(k-2) \\
x_{10}(k+1)= & \left(30 \otimes x_{9}(k-2)\right) \oplus\left(20 \otimes x_{8}(k-1)\right)
\end{aligned}
$$

Berdasarkan Tabel 1 jumlah variabel adalah 10 variabel dan jumlah armada maksimum adalah 3 armada pada setiap trayek, maka $n=10$ dan $M=3$. Sehingga ada 3 buah matriks $A_{p}$ dengan $p=\{1,2,3\}$ dan masingmasing berukuran $10 \times 10$.

Matriks $A_{1}=\varepsilon(10,10)$ karena tidak ada pemberangkatan yang menunggu kedatangan armada yang berangkat kedua, kemudian matriks $A_{2}$ dan $A_{3}$ adalah

$$
\begin{aligned}
A_{2} & =\left(\begin{array}{llllllllll}
\varepsilon & \varepsilon & \varepsilon & \varepsilon & \varepsilon & \varepsilon & \varepsilon & \varepsilon & \varepsilon & 20 \\
15 & \varepsilon & \varepsilon & \varepsilon & \varepsilon & \varepsilon & \varepsilon & \varepsilon & \varepsilon & \varepsilon \\
15 & \varepsilon & \varepsilon & \varepsilon & \varepsilon & \varepsilon & \varepsilon & \varepsilon & \varepsilon & \varepsilon \\
\varepsilon & \varepsilon & \varepsilon & \varepsilon & \varepsilon & 20 & 15 & \varepsilon & \varepsilon & \varepsilon \\
\varepsilon & \varepsilon & \varepsilon & \varepsilon & \varepsilon & 20 & 15 & \varepsilon & \varepsilon & \varepsilon \\
\varepsilon & \varepsilon & \varepsilon & \varepsilon & 20 & \varepsilon & \varepsilon & \varepsilon & \varepsilon & \varepsilon \\
\varepsilon & \varepsilon & \varepsilon & 15 & \varepsilon & \varepsilon & \varepsilon & \varepsilon & \varepsilon & \varepsilon \\
\varepsilon & \varepsilon & \varepsilon & \varepsilon & \varepsilon & 20 & 15 & \varepsilon & \varepsilon & \varepsilon \\
\varepsilon & \varepsilon & \varepsilon & \varepsilon & \varepsilon & \varepsilon & \varepsilon & \varepsilon & \varepsilon & \varepsilon \\
\varepsilon & \varepsilon & \varepsilon & \varepsilon & \varepsilon & \varepsilon & \varepsilon & 20 & \varepsilon & \varepsilon
\end{array}\right) \\
A_{3} & =\left(\begin{array}{llllllllll}
\varepsilon & \varepsilon & \varepsilon & \varepsilon & \varepsilon & \varepsilon & \varepsilon & \varepsilon & \varepsilon & \varepsilon \\
\varepsilon & \varepsilon & \varepsilon & \varepsilon & \varepsilon & \varepsilon & \varepsilon & \varepsilon & \varepsilon & \varepsilon \\
\varepsilon & \varepsilon & \varepsilon & \varepsilon & \varepsilon & \varepsilon & \varepsilon & \varepsilon & \varepsilon & \varepsilon \\
\varepsilon & \varepsilon & 30 & \varepsilon & \varepsilon & \varepsilon & \varepsilon & \varepsilon & \varepsilon & \varepsilon \\
\varepsilon & \varepsilon & 30 & \varepsilon & \varepsilon & \varepsilon & \varepsilon & \varepsilon & \varepsilon & \varepsilon \\
\varepsilon & \varepsilon & \varepsilon & \varepsilon & \varepsilon & \varepsilon & \varepsilon & \varepsilon & \varepsilon & \varepsilon \\
\varepsilon & \varepsilon & \varepsilon & \varepsilon & \varepsilon & \varepsilon & \varepsilon & \varepsilon & \varepsilon & \varepsilon \\
\varepsilon & \varepsilon & 30 & \varepsilon & \varepsilon & \varepsilon & \varepsilon & \varepsilon & \varepsilon & \varepsilon \\
\varepsilon & 30 & \varepsilon & \varepsilon & \varepsilon & \varepsilon & \varepsilon & \varepsilon & \varepsilon & \varepsilon \\
\varepsilon & \varepsilon & \varepsilon & \varepsilon & \varepsilon & \varepsilon & \varepsilon & \varepsilon & 30 & \varepsilon
\end{array}\right)
\end{aligned}
$$


Maka diperoleh matriks representatif yang menggambarkan sinkronisasi dari ketiga trayek angkutan pedesaan yang memenuhi $x(k+1)=\bigoplus_{p=1}^{M}\left(A_{p} \otimes x(k+1-p)\right)$ dengan matriks A adalah sebagai berikut:

$$
A=\left(\begin{array}{ccc}
A_{1} & A_{2} & A_{3} \\
E & \varepsilon(10,10) & \varepsilon(10,10) \\
\varepsilon(10,10) & E & \varepsilon(10,10)
\end{array}\right)
$$

Selanjutnya dengan bantuan GUI maxplus pada software Scilab, dengan menerapkan teorema 2, diperoleh nilai eigen $l=10$. Interpretasi dari nilai eigen ini adalah bahwasanya periode keberangkatan atau waktu tunggu angkutan perdesaan di masing-masing titik adalah setiap 10 menit sekali. Selanjutnya karena vektor eigen yang diperoleh dapat dibagi ke dalam dua interval waktu keberangkatan, maka terdapat dua jadwal keberangkatan bagi seluruh armada angkutan perdesaan di ketiga trayek tersebut. Jadwal keberangkatan angkutan perdesaan interval pertama dengan waktu keberangkatan awal menit ke-0 yaitu angkutan pedesaan $x_{2}, x_{3}, x_{7}$ dan $x_{9}$ sedangkan untuk interval kedua dengan waktu keberangkatan awal menit ke-5 yaitu angkutan perdesaan $x_{1}, x_{4}, x_{5}, x_{6}, x_{8}$ dan $x_{10}$.

\section{Kesimpulan}

Hasil penelitian menunjukkan bahwa aljabar max-plus dapat diterapkan pada permasalahan penjadwalan armada angkutan perdesaan di Jombang, yaitu trayek B,C dan G, dan menghasilkan waktu tunggu selama 10 menit disetiap titik. Selanjutnya interval waktu yang diperoleh dibagi menjadi dua waktu keberangkatan yang dapat menjamin keberadaan angkutan umum disetiap titik pada jam pulang sekolah.

\section{Penghargaan}

Ucapan terima kasih kami sampaikan kepada Direktorat Riset dan Pengabdian Masyarakat, Direktorat Jenderal Penguatan Riset dan Pengembangan, Kementerian Riset, Teknologi, dan Pendidikan Tinggi atas dana yang diberikan untuk mendukung pelaksanaan penelitian ini.
Sesuai dengan kontrak penelitian, Nomor:086/SP2H/P/K7/KM/2016, penelitian ini merupakan penelitian yang lolos pembiayaan pada skem penelitian dosen pemula (PDP) tahun pendanaan 2017.

\section{Referensi}

[1] J. R. Joesoef, A. Prasetia, and U. Gajayana, "DI PROVINSI JAWA TIMUR Media Trend Vol 11 No . 1 Maret 2016, hal 1-19," vol. 11, no. 1, pp. 1-19, 2016.

[2] D. E. Kinerja and P. Sektoral, "Laporan Akhir," 2012.

[3] N. Rakhmawati, "Study of School Bus PlanningBy Using Max-Plus Interval Algebra," pp. 252-255, 2015.

[4] R. M. Mubarok, "Analisis kinerja angkutan umum kabupaten jombang," 2013.

[5] Aminah. S, "Transportasi Publik dan Aksesibilitas Masyarakat Perkotaan”, 2004.

[6] Molnárová. M, “Generalized Matrix Period In Max-Plus Algebra”, 404, 345366.

https://doi.org/10.1016/j.laa.2005.02.033, 2005.

[7] Fahim. K, et all, "Aplikasi Aljabar MaxPlus Pada Pemodelan Dan Penjadwalan Busway Yang Diintegrasikan Dengan Kereta Api Komuter", 1(1), 1-6, 2013. 